\title{
Lower Secondary School Students' Attitudes Toward Computer-Supported Laboratory Exercises
}

\author{
doi:10.3991/ijet.v5s2.1228
}

\author{
A. Špernjak, M. Puhek and A. Šorgo \\ University of Maribor, Maribor, Slovenia
}

\begin{abstract}
In Science teaching laboratory work is recognized as one of the cornerstones. In school science laboratory work computers can be used as computer supported laboratory (real) and as virtual laboratory. In the first case "real" laboratories involve bench top experiments utilizing data acquisition systems while "virtual" laboratory entails interactive simulations and animations. Lower secondary school students in age between 11 and 15 performed three laboratory exercises (Activity of yeast, Gas exchange in breathing, Heart rate) as classic, computer-supported and virtual laboratory. As a result of testing we know that all three methods are suitable even for younger students. When they were asked which method they liked the most, their first choice was computer-supported laboratory, followed by classic laboratory, and virtual laboratory at the end. Additionally recognized weak and strong sides of used methods are discussed.
\end{abstract}

Index Terms-Biology, computer-supported laboratory, education, laboratory work, lower secondary school, simulations

\section{INTRODUCTION}

In the second half of the past century some major findings shaped future of the Science education. The most important was recognition that active teaching methods are a keystone to higher order thinking. Different theories under cover name constructivism emerge on this basis. As a practical consequence laboratory work was introduced into curriculum of Science subjects at all school levels [1], [2], [3], [4]. Later it was recognized that not only introduction of the laboratory work into teaching but a method how it is performed is important in achieving competencies. Inquiry and problem based methods were recognized as more favorable than laboratory experiments performed in a "cook book" fashion [5], [6], [7], [8]. With the advent of computers their possibility to improve teaching was immediately recognized and they were introduced into schools shortly after their prices declined to the acceptable levels. As early as 1980 Taylor [9] recognized three types of computer (ICT) work in education: tutor, tool and tutee.

In laboratory work computers are used (besides in other subjects as typewriter, source of information, advanced calculator and multimedia) as computer-supported laboratory (real) and virtual laboratory. In the first case "real" laboratories involve bench top experiments utilizing data acquisition systems while "virtual" laboratory entails interactive simulations and animations [10]. Advantages and disadvantages are reported for both »real« and "virtual" laboratory as well as for classical laboratory [11].

Our intention is to examine suitability of virtual and computer supported laboratory in Biology teaching in primary and lower secondary school in the next years. The framework of our research is the project funded by European Social Funds "Development of Science competences" with Faculty of Natural Sciences and Mathematics at University of Maribor as its promoter.

In the first phase we were in search of answers to the research questions: "What kind of laboratory work students prefer the most?" and "Are there any differences among students based on gender, age and school grades?"

Results are planned to be used in the development of new generation of tested experiments to help teachers introduce active methods of teaching into their daily routine.

\section{METHODS}

To examine differences we prepared triplets of laboratory exercises. Every laboratory work in a triplet is prepared as classical laboratory work, computer-supported (real) laboratory work and interactive virtual laboratory work. Initially well known and easy to perform laboratory exercise from current school practice was chosen. In the second phase it was adapted into computerized laboratory exercise. Vernier's interface, sensors and software (http://www.vernier.com) were used, but other acquisition systems would work as well. Data obtained in computerized laboratory were used to produce realistic graphs in interactive simulations developed for the purpose of the research. For hands on laboratory both in classical and computerized version glassware common in school laboratory was used. Until now three such triplets were tested. The first one is laboratory work named the activity of yeast, the second one is the examination of heart rate, and the third one is the consumption of oxygen in respiration

Interactive simulations were programmed in Microsoft's Visual Basic 6.0. Every simulation is self-standing auto-executive programs, what was recognized as advance in comparison with Sun's Easy Java Simulations, what was our other choice. The main reason was that auto-executive programs do not need additional software uploaded on computer, what makes them easier to spread among computer users. In all three cases after setting initial parameters click on execute button will run a simulation. Students can reset initial data with no need to close the program for another turn. 
Until now we tested experiments on 198 students between 11 and 15 years. Every student performs all three experiments, but each experiment in a different way. For example the activity of yeast as classical laboratory, heart rate as computer-supported laboratory and oxygen consumption as interactive simulation. In such way results were collected as $3 \times 3$ matrix, what enabled us to search for differences between groups. Students' opinions and personal data were collected using a questionnaire developed for the purpose of the research.

Due to privacy reasons, we do not have any possibility to test students' performance levels or intelligence, we used final school grade as one of the possible scales. In Slovenia final grades at the end of the year are compiled and students are recognized as excellent, very good, good, fair and do not pass. In our group there were 84 (42.4\%) excellent, 71 (35.9\%) very good, 32 (16.2\%) good and $3(1.5 \%)$ fair students. Eight (4\%) students left the field in a questionnaire blank. Later in the analyses good and fair students were merged in a single group.

\section{DESCRIPTION OF LABORATORY EXERCISES}

\section{A. Activity of yeast}

This exercise is standard due to safety reasons, availability of materials and possibility to be used at different points and contexts (rising of bread, fermentation, enzymatic activity, etc.) in teaching. The effect of temperature on activity of yeast is examined. The speed of production of carbon dioxide is measured. In real experiments (both classic and computerized) the suspension of yeast obtained in local store was prepared. A spoon of table sugar was added to the suspension. The suspension was divided into three bottles and put into water baths with different temperature. Ice cubs were added into the first one, the second one stayed at the room temperature, and the third one was warmed at the temperature between 35 and $40^{\circ} \mathrm{C}$. In "classical" variant rising of balloons indicate the speed of reactions (see Fig. 1), in the computerized laboratory rising of gas pressure was measured using gas pressure sensors and in interactive simulations results are presented as graphs and flasks with balloons (see Fig. 2).

\section{B. Gas exchange in breathing}

The main goal of the exercise is to show, that the composition of gasses in inhaled air is different than in exhaled air.

Oxygen is consumed in respiration and carbon dioxide is released. The differences are not constant but are in correlation with the activity.

In classical variant a volunteer has to exhale air through a straw in a sealed plastic bag with known volume. After that exhaled air is poured into distilled water. Carbon dioxide forms weak acid, with water what results in change of $\mathrm{pH}$.

The drop of $\mathrm{pH}$ can be registered with $\mathrm{pH}$ meter or as a change in color of bromthymol blue as indicator. In computerized version of the experiment a volunteer has to exhale air into a plastic bag and gas oxygen sensor is used to record changes.

Experiments can be repeated under other conditions (after some kind of activity) with the same or other volunteers (see Fig. 3). In interactive simulations changes are present as a drop in the concentration of oxygen in in-

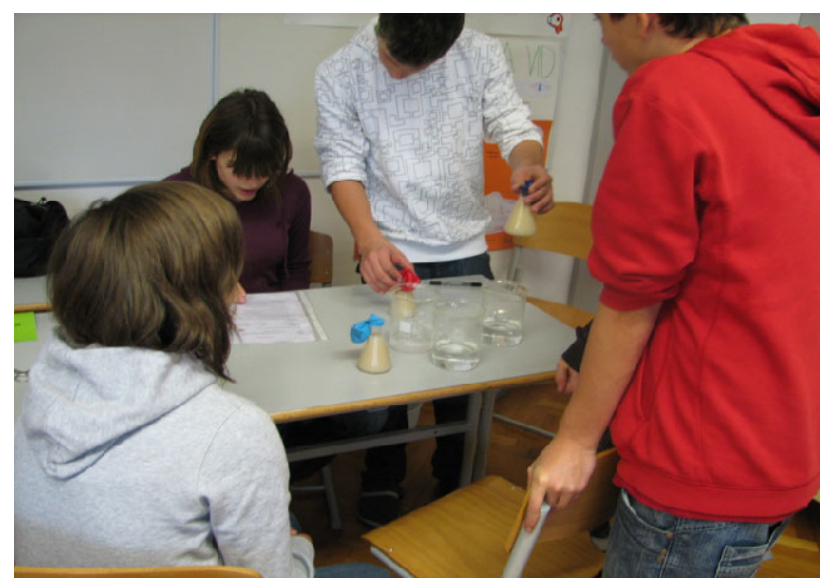

Figure 1. The "classical" variant Activity of yeast laboratory exercise

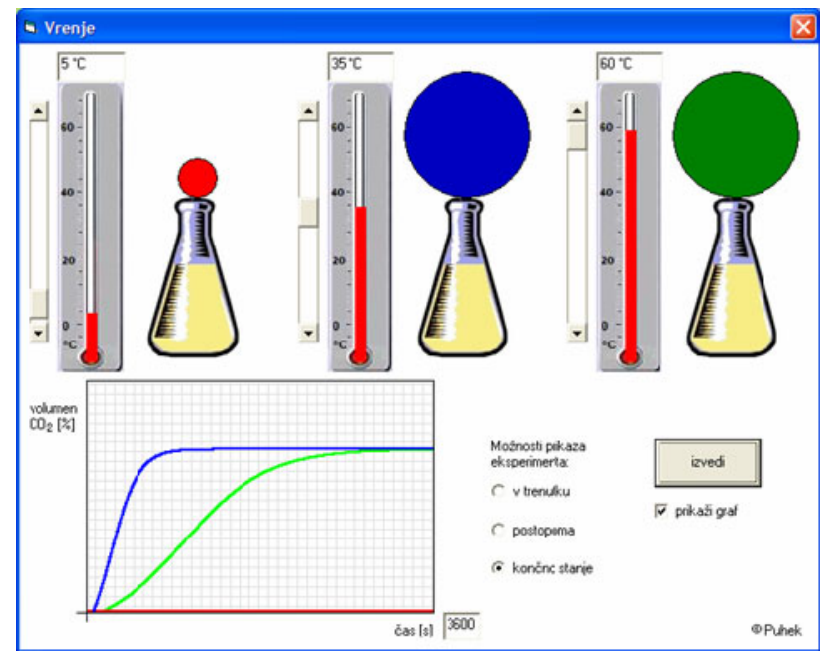

Figure 2. Front page of the simulation of the Activity of yeast laboratory exercise

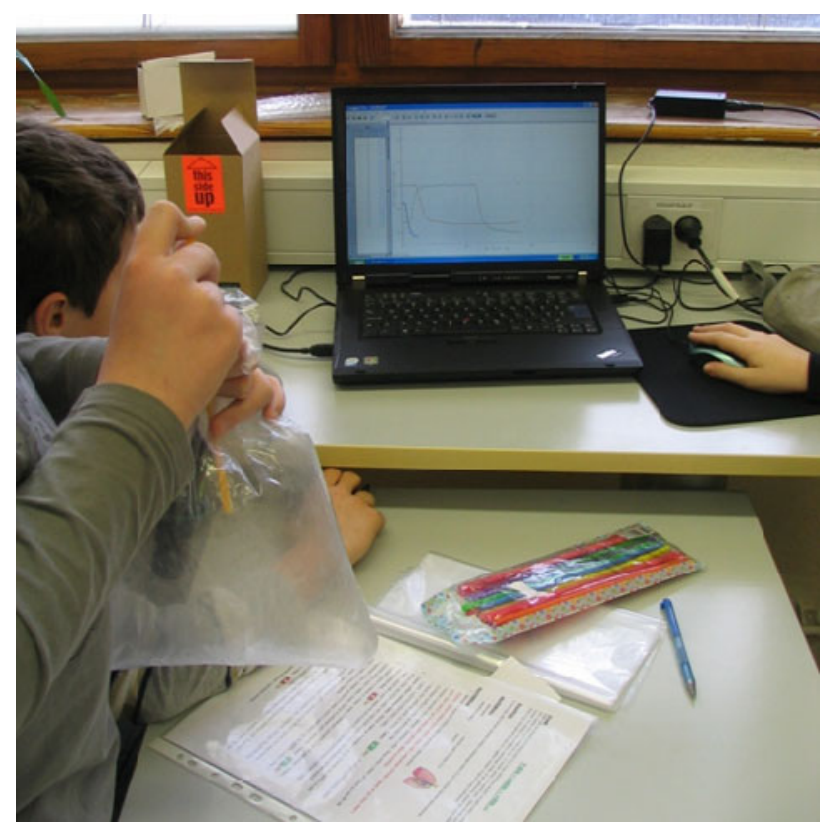

Figure 3. The computerized laboratory gas exchange in breathing 
haled and rise of exhaled carbon dioxide in exhaled air (see Fig 4).

\section{Heart rate}

The main task of the exercise is to examine differences in heart rate among students, changes caused by some sort of activity and the speed of recover at initial state (see Fig. 5). Stop watch was and measure of arterial pulse is classical method, heart rate monitor was used in computerized laboratory.

In simulations students can choose between three different persons of different sex (student, sportsman and overweighed) and examine differences in heart rates before and after activity or between persons (see Fig 6).

\section{RESULTS AND DISCUSSION}

Computerized experiments are the first option for very good and excellent students, while for the students who belong to the group; good interactive simulations are the first choice (see Table 1). It was interesting to find out, that very good students generally do not like simulations. We can speculate that in this group of students there are the most active students and they found simulations boring. Our results are supported by the evidence that the greatest percentage of the students who choose classical laboratory as the first option belonged to this group.

From the results (see Table 2) we can conclude that computerized experiments be in general the first choice for students, the second choice would be classical laboratory and the third option interactive simulations. Girls are more enthusiastic than boys by working in the computerized laboratory, while boys outnumbered girls by choosing virtual laboratory. The number of boys and girls who chose classic laboratory as the first option is almost equal. Differences among students coming from different classes in combination with sex are at the moment, due to insufficient number of participants, only provisional and have to be elaborated in details, when sufficient number of students will be tested. For example boys from the ninth class were represented in a sample with $4.5 \%$, so the results are greatly biased.

TABLE I.

CHOICE OF SEVERAL LABORATORY WORK METHOD AS TO SCHOLAR'S GRADE

\begin{tabular}{ccccccccc}
\hline Grade & Good & \multicolumn{2}{c}{$\begin{array}{c}\text { Very } \\
\text { good }\end{array}$} & Excellent & \multicolumn{2}{c}{ Total } \\
\hline & $\mathbf{N}$ & $\%$ & $\mathbf{N}$ & $\%$ & $\mathbf{N}$ & $\%$ & $\mathbf{N}$ & $\%$ \\
\hline $\begin{array}{c}\text { Classical } \\
\text { experiment }\end{array}$ & 10 & 32.2 & 23 & 37.1 & 23 & 29.5 & 56 & 32.7 \\
\hline $\begin{array}{c}\text { Computer- } \\
\text { experiment }\end{array}$ & 9 & 28.1 & 33 & $\mathbf{5 3 . 2}$ & 35 & $\mathbf{4 4 . 8}$ & 77 & $\mathbf{4 5 . 0}$ \\
\hline $\begin{array}{c}\text { Interactive } \\
\text { simulation }\end{array}$ & 12 & $\mathbf{3 8 . 7}$ & 6 & 9.7 & 20 & 25.7 & 38 & 22.3 \\
\hline Total & 31 & & 62 & & 78 & & 171 & \\
\hline
\end{tabular}

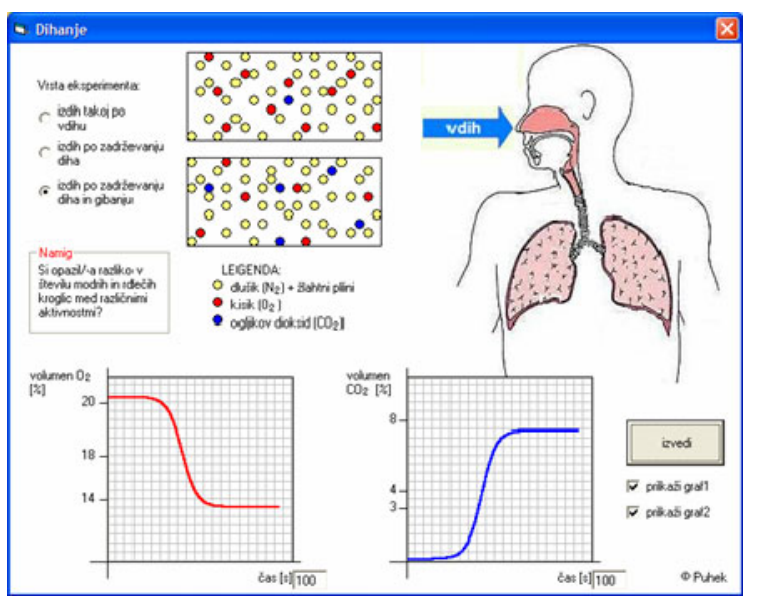

Figure 4. Front page of the simulation of the Activity of yeast laboratory

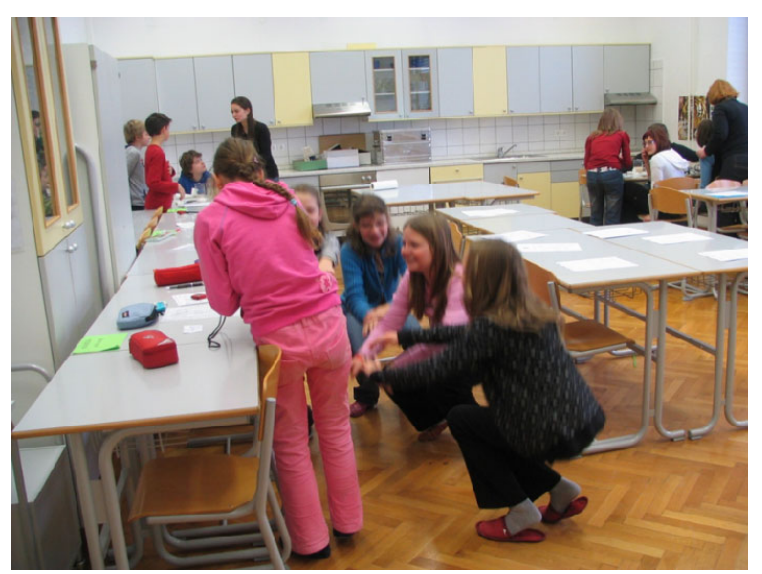

Figure 5. The classical method Heart rate by some sort of activity

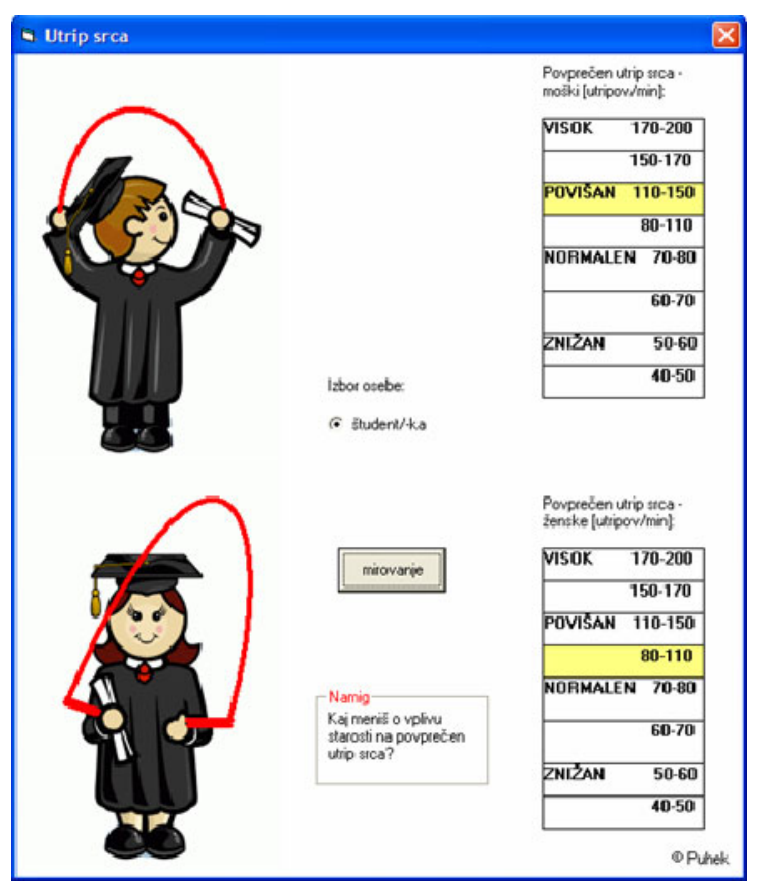

Figure 6. Front page of Heart rate 
TABLE II.

THE MOST POPULAR OF SEVERAL METHOD LABORATORY WORK AS TO SEX AND AGE STAGE

\begin{tabular}{|c|c|c|c|c|c|c|c|c|c|c|c|c|}
\hline Class & \multicolumn{3}{|c|}{5} & \multicolumn{2}{|c|}{6} & \multicolumn{2}{|c|}{7} & \multicolumn{3}{|c|}{8} & \multicolumn{3}{|c|}{ Total } \\
\hline Sex & $\mathbf{F}$ & $\mathbf{M}$ & $\mathbf{F}$ & $\mathbf{M}$ & $\mathbf{F}$ & $\mathbf{M}$ & $\mathbf{F}$ & $\mathbf{M}$ & $\mathbf{F}$ & $\mathbf{M}$ & $\mathbf{F}$ & $\mathbf{M}$ \\
\hline & $\%$ & $\%$ & $\%$ & $\%$ & $\%$ & $\%$ & $\%$ & $\%$ & $\%$ & $\%$ & $\%$ & $\%$ \\
\hline $\begin{array}{c}\text { Classical } \\
\text { experiment }\end{array}$ & 38.6 & 30.0 & 29.4 & 41.7 & 30.6 & 25.0 & 34.8 & 29.1 & 34.8 & $\mathbf{6 2 . 5}$ & 33.0 & 34.8 \\
\hline $\begin{array}{c}\text { Computer- } \\
\text { experiment }\end{array}$ & 30.7 & $\mathbf{4 0 . 0}$ & $\mathbf{5 8 . 8}$ & 33.3 & $\mathbf{5 5 . 6}$ & $\mathbf{5 8 . 3}$ & 39.1 & $\mathbf{3 7 . 6}$ & 43.5 & 12.5 & $\mathbf{4 7 . 3}$ & 37.9 \\
\hline $\begin{array}{c}\text { Interactive } \\
\text { simulation }\end{array}$ & 30.7 & 30.0 & 11.8 & 25.0 & 13.8 & 16.7 & 26.1 & 33.3 & 21.7 & 25.0 & 19.7 & 27.3 \\
\hline
\end{tabular}

\section{CONCLUSIONS}

Our first finding was that students are not the greatest barrier in introducing computerized and virtual interactive laboratory exercises into teaching practice. According our experience they were able to perform exercises as early as in the fifth class. Furthermore it seems that this is not the lowest age that has to be tested in the future. Students found the greatest interest in computer supported real laboratory, followed with classical laboratory and virtual laboratory at the end. Because every method has some advantages and also benefits of manual manipulative skills in real laboratory, simultaneous presentations of graphs in line with the experiment, or safety and possibility to experiment at home in virtual laboratory. The same is with the obstacles. In virtual laboratory a student does not practice manipulative skills and results are »idealised «.

In classical laboratory a lot of precious time is used for data manipulation, and construction of graphs is obsolete in computerized laboratory. Because of the recognized benefits and obstacles we would recommend that all three methods are used in a classroom interchangeably.

The major possible excuses not to introduce laboratory work with computers are equipment and teachers. In reality computers are already available at all Slovene primary schools and large sums were invested into ICT in the last years. When computers are available then interactive virtual laboratory exercises are only small additional programmes with a couple of icons added to a desktop. Hardware and software needed for computerized laboratory work may be greater problem. Momentarily the equipment of different manufacturers is commercially available at reasonable prices. We recognize the greatest obstacle in teachers, who mostly do not want to leave well tracked ways of direct teaching.

\section{REFERENCES}

[1] M. Pickering, "Are Lab Courses a Waste of Time?", The Chronicle of Higher Education, p.80. (February 19) 1980.

[2] J. W. Beatty and B. E. Woolnough, "Practical Work in 11-13 Science: the context, type and aims of current practice", British Educational Research Journal, no. 8, p. 23-30, 1982. (doi:10.1080/0141192820080103)

[3] P. A. Kirschne and A. Meester, "The laboratory in higher science education. Problems, premises and objectives". Higher education, vol. 17, p. 81 - 98, 1988. (doi:10.1007/BF00130901)
[4] J. Michael, "Where's the evidence that active learning works?", Advances in Physiology Education, vol. 30, p. 159-167, 2006. (doi:10.1152/advan.00053.2006)

[5] D. S. Domin, "A review of laboratory instruction styles", Journal of Chemical Education, vol: 76, no. 4, p. 543-547, 1999.

[6] W. Killerman, "Research into biology teaching methods", Journal of Biological Education, vol. 33, no. 1, p. 4-9, 1998.

[7] A. H. Johnstone and A. Al-Shuaili, "Learning in the laboratory; some thoughts from the literature". University Chemistry Education, no. 5, p. 42-51, 2001.

[8] P. A. Kirchner, J. Sweller, R. E. Clark, "Why Minimal Guidance During Instruction Does Not Work: An Analysis of the Failure of Constructivist, Discovery, Problem-based, Experiental, and Inquiry-based Teaching". Educational Psychologist, vol. 41, no.2, p. 75-86, 2006. (doi:10.1207/s15326985ep4102_ 1)

[9] R. P. Taylor, "Reflection on The Computer in the School. Contemporary Issues in Technology and Teacher Education", vol. 3, no.2, p. 253-274, 2003.

[10] S. Kocijančič and C. O'Sullivan, "Real or virtual laboratories in science teaching - is this actually a dilemma?", Informatics in education, vol. 3, no.2, p. 239-250, 2004.

[11] A. Šorgo, "Meaning of laboratory work in biology classes", Didactica Slovenica - Pedagoška obzorja, vol. 22, no. 3-4, p. 2837, 2007. (in Slovenian)

[12] http://www.vernier.com $\left(17^{\text {th }}\right.$ January 2009).

\section{AUTHORS}

A. Špernjak is an Assistant in Didactics of Biology at the Faculty of Natural Sciences and Mathematics University of Maribor, Slovenia (e-mail: andreja.spernjak@unimb.si).

M. Puhek is an Assistant in Biology Department at the Faculty of Natural Sciences and Mathematics University of Maribor, Slovenia (e-mail: miropuhek@gmail.com).

A. Šorgo is a Professor in Didactics of Biology at the Faculty of Natural Sciences and Mathematics, University of Maribor, Slovenia (e-mail: andrej.sorgo@uni-mb.si).

Ministry of Education and Sport of Republic of Slovenia and European Social Fund in the frame of "Project: Development of Natural Science Competences" performed at the Faculty of Natural Sciences of University of Maribor

This article was modified from a presentation at The 32nd International Convention MIPRO on information and communication technology, electronics and microelectronics., in 25-29 May 2009, Opatija, Croatia. Manuscript received, 16 February 2010. Published as resubmitted by the authors 1st March 2010. 